\title{
PENGELOLAAN AIR TANAH DAN INTRUSI AIR LAUT
}

\author{
Oleh: \\ Arie Herlambang dan R. Haryoto Indriatmoko \\ Kelompok Teknologi Pengelolaan Air Bersih dan Limbah Cair, Pusat Pengkajian dan Penerapan Teknologi
} Lingkungan, BPPT

\begin{abstract}
Coastal Aquifer System of Jakarta consist of unconfined aquifer layers, confined aquifer I and confined aquifer II. Resources of groundwater is very important for Jakarta City, for drinking water, industry, hotel, government offices and various other facility. Important considering of groundwater resources of Jakarta hence needed an effort to preserve the groundwater and awake its continuity by conducting a system management of groundwater. Model used for the management of groundwater system of aquifer coastal referred as Groundwater Model Simulation and Optimization of Quasi Three Dimension (OPT-Q3D). Model simulation and optimization represent computer model of quasi-three dimensions with method of finite difference used for the operation of infiltration of sea water. This model can conduct current simulation of groundwater flow, head of fresh water and brine, and describe the movement of interface fresh water and sea water. The model can also make optimization of system aquifer with single or multi layers. Jakarta Groundwater Basin assumed consist three layers of aquifer separated by impermeable layer. Applying of groundwater simulation model in Jakarta can give information regarding balance of groundwater, head of freshwater, head of brine, interface brine and freshwater, map of brine distribution and bargain in each; every aquifer. Herein after model optimization will yield various information able to wear upon which consideration to manage the amount of pumping of optimal ground water every area in each layer of aquifer, amount of optimal pumping, optimal freshwater head, head of optimal brine and map of infiltration.
\end{abstract}

Kata Kunci : Air Tanah, Pengelolaan, Intrusi Air Laut, Modeling

\section{PENDAHULUAN}

\section{$1.1 \quad$ Latar Belakang}

Dengan semakin berkembangnya penduduk perkotaan, maka tekanan terhadap kualitas air permukaan juga semakin meningkat. Sementara ini pelayanan air minum dengan sistem perpipaan oleh pemerintahmasih terbatas, oleh karena itu dibanyak tempat air tanah merupakan sumber air alternatif yang paling memungkinkan bagi masyarakat untuk mendapatkan dengan mudah tanpa memerlukan proses pengolahan yang mahal.

Peraturan mengenai pengambilan air tanah juga telah ada, tetapi dalam pelaksanaan-nya masih sulit dikendalikan, karena air merupakan kebutuhan pokok dan pemerintah belum dapat menyediakan sarana air bersih secara penuh, sehingga masyarakat tetap mengambil air tanah dengan berbagai alasan dan sulit dikendalikan. Kesulitan ini tampak dari tidak adanya data tentang jumlah pemompaan yang tepat dan posisi pengambilannya.

Perhitungan pemakaian air tanah akhir-akhir ini selalu dikaitkan dengan tingkat pelayanan air minum oleh perusahaan daerah (PDAM). Dengan asumsi bahwa yang tidak memakai air PDAM akan memakai air tanah. Sebagai contoh untuk kota Jakarta, dengan total kapasitas produksi rill $15.430 \mathrm{l} / \mathrm{dtk}$ dan terjual $8.102 \mathrm{l} / \mathrm{dtk}$ dengan 663.000 satuan sambungan (setara dengan 4,5 juta orang). Dengan jumlah penduduk yang telah mencapai 10.421.948 jiwa dan asumsi tingkat kebutuhan untuk kota metropolitan 250 liter/orang/hari, maka kebutuhan air bersih kota Jakarta mencapai $30.156 \mathrm{l} / \mathrm{dtk}$. Dengan demikian pemakaian air tanah oleh masyarakat masih cukup besar, yaitu $22.054 \mathrm{l} / \mathrm{dtk}$ atau 1,9 juta $\mathrm{m} 3 / \mathrm{hari}$.

Seperti diketahui bahwa pengambilan air tanah tidak merata, kondisi dapat dilihat dari peta sebaran sumur dalam, dan peta muka air tanah Jakarta. Pada tempat-tempat yang beban pengambilan air tanahnya besar, permukaan air 
tanahnya akan turun lebih dalam dibanding daerah sekitarnya. Jika dilihat dari prediksi beban pengambilan air tanah di wilayah Jakarta, Jakarta pusat mempunyai beban yang paling berat dalam pengambilan air tanahnya, mencapai 8.861,46 $\mathrm{m} 3 /$ hari/km2 (Tabel 1), kondisi terberat ini sudah dialami Jakarta Pusat sejak sebelum tahun 1990 yang ditunjukkan dengan penurunan muka air tanah yang signifikan pada tiap lapisan akuifernya.

Potensi air tanah Jakarta menurut JWRMS (1994), untuk air tanah dalam adalah $2.476 \mathrm{l} / \mathrm{dtk}$ dan air tanah dangkal adalah 25.720

l/dtk (Total $28.196 \quad \mathrm{l} / \mathrm{dtk}$ ), dengan mempertimbangkan prediksi pemakaian air

tanah oleh masyarakat, maka potensi air tanah yang tersisa tinggal $6.141 \mathrm{l} / \mathrm{dtk}$. Adanya sisa potensi ini yang menimbulkan salah persepsi dibanyak kalangan yang menyatakan bahwa Jakarta masih aman air tanahnya. Padahal sisa potensi yang hanya $21,7 \%$ itu sangat mengkhawatirkan, karena sudah melebihi 50\% dari potensi air tanah yang ada. Dalam Cisadane River Basin Development Feasability Study tahun 1987, diketahui bahwa batas pengambilan air tanah aman untuk Cekungan Air Tanah Jakarta adalah $3.600 \mathrm{l} / \mathrm{dtk}$ dan ketika itu pengambilan air tanah di Jakarta telah mencapai $6.800 \mathrm{l} / \mathrm{dtk}$. Oleh karena itu rekomendasi yang muncul saat itu adalah perlu peningkatan kapasitas pelayanan air bersih sistem perpipaan yang berasal dari pengolahan air permukaan untuk mengurangi tekanan terhadap eksploitasi air tanah yang berlebihan.

Pengambilan air tanah yang berlebihan akan menimbulkan ruang kosong dibawah tanah yang memungkinkan terjadi proses kompaksi akibat tekanan beban tanah atau batuan di atasnya, yang tercermin dipermukaan sebagai amblesan (subsiden) yang datangnya dapat secara perlahan-lahan atau tiba-tiba. Perhitungan peluang kejadian amblesan ini sulit diprediksi, sama seperti menghitung peluang kejadian gempa bumi, karena harus dimonitor secara terusmenerus agar titik kritisnya tidak terlampaui. Pada akuifer yang dekat dengan pantai, kekosongan akibat pengambilan air tanah yang berlebihan dapat mengakibatkan perubahan kesetimbangan hidrolik antara air tekanan air tawar dan air laut, yang mengkibatkan masuknya air laut ke arah darat atau yang dikenal selama ini dengan intrusi air laut. Oleh karena itu untuk akuifer tipe pantai masuknya air laut dapat menghambat kejadian amblesan. Namun demikian kualitas air tanahnya menjadi menurun dari tahun ke tahun akibat masuknya air laut dan merembesnya pencemaran limbah domestik lebih jauh pada air tanah dangkal.

\subsection{Permodelan Air Tanah}

Kondisi akuifer tipe pantai seperti Jakarta, secara alami cukup ideal, karena wilayah imbuhan (recharge area) dan posisi lapisan akuifer cukup jelas. Permasalahan yang muncul dalam pemodelan adalah bagaimana menyederhanakan bentuk alam yang rumit menjadi bentuk yang sederhana dengan mempertimbangkan faktorfaktor penentunya. Dalam pembuatan model air tanah salah satu faktor yang menjadi kendala adalah bagaimana menentukan kapasitas pemompaan. Kondisi ini tidak hanya terjadi di Indonesia, kapasitas pemompaan sulit diprediksi karena lemahnya sistem database dan penegakan peraturan.

Di beberapa daerah kondisi hidrogeologi pantai secara sederhana digambarkan sebagai suatu individu lapisan akuifer taktertekan, lapisan akuifer kepulauan atau akuifer tertekan (Gambar 1). Secara lebih umum lagi susunan hidrogeologi sistem akuifer dalam lingkungan pantai adalah suatu jajaran lapisan dengan berbagai kondisi terdiri dari kombinasi lapisan akuifer tertekan dan tak tertekan. Kondisi lapisan akuifer daerah pantai pada umumnya tidak seideal dalam teori yaitu yang hanya terdiri dari lapisan akuifer tunggal akan tetapi pada kenyataannya amatlah kompleks. Lapisan akuifer yang paling atas dapat sebagai lapisan akuifer tertekan atau dapat juga sebagai lapisan tak tertekan. Tebal tipis lapisan akuifer di berbagai tempat tidak sama (seragam). Juga dimungkinkan terdiri dari lensa-lensa akuifer yang amat komplek. Kondisi yang tidak seideal seperti dalam teori adalah yang paling sering dijumpai.

Untuk menggambarkan kondisi sistem pantai, suatu gambaran penampang hidrogeologi yang ideal ditunjukkan dengan suatu sistem akuifer pantai berlapis yang lepas pantainya diperluas hingga ke dasar tebing seperti terlihat pada Gambar 2. Dalam keadaan yang alami, kondisi yang tidak terganggu, terdapat suatu garis kemiringan hidrolik seimbang yang mengarah kelaut, dalam setiap akuifer dengan air tawar yang mengalir kelaut (Gambar 2.a). Di lapisan paling atas pada akuifer tak tertekan air tawar mengalir bebas kelaut. Dibawahnya pada akuifer tertekan air tawar mengalir ke laut melalui bocoran terus ke lapisan atas dan atau mengalir bebas ketebing. Dibawah kondisi "steady-state" suatu "interface" yang tidak berubah dipertahankan bentuk dan posisinya ditentukan oleh potensi air tawar dan garis kemiringan. Pada suatu kasus sistem satu lapisan, air laut pada dasarnya akan statis pada kondisi "steady-state". Pada suatu sistem lapisan, jika ada kebocoran vertikal air tawar kedalam 
suatu daerah air asin, pada daerah ini air yang bercampur akan menjadi tidak statis.

Pada kenyataannya, pemisahan "interface" air tawar dan air asin pada suatu daerah bersifat transisi. interface transisi terbentuk karena efek difusi dan penyebaran secara mekanik. Cooper (1959) dan Kohout (1964) telah menunjukkan bahwa dalam daerah campuran, air asin yang ditambah air yang kurang pekat dari air laut semula, menyebabkanya naik dan bergerak kelaut sepanjang "interface" (Gambar 3). Ini menyebabkan suatu siklus aliran air asin dari laut, dasar samodra, ke daerah campuran dan kembali ke laut. Siklus aliran ini terjadi dibawah kondisi "steady-state". Perubahan di dalam tanah oleh imbuhan atau perubahan luah aliran dalam daerah air tawar, menyebabkan perubahan "interface".

Penurunan aliran air tawar yang masuk ke laut menyebabkan "interface" bergerak ke dalam tanah dan menghasilkan intrusi air asin ke dalam akuifer. Sebaliknya suatu peningkatan aliran air tawar mendorong "interface" ke arah laut. Laju gerakan "interface" dan respon tekanan akuifer tergantung kondisi batas dan sifat akuifer pada kedua sisi "interface". Pada sisi dengan air asin dapat bergerak kedalam atau keluar, pada sistem akuifer efek dari gerakan interface mempengaruhi perubahan debit air tawar di lepas pantai. Dalam suatu sistem akifer berlapis, air asin dapat masuk akuifer oleh aliran melalui akuifer tersingkap atau bocoran yang melewati lapisan pembatas atau lantai laut (Gambar 1.2 b). Oleh karena itu agar mengetahui sistem akuifer pantai, perlu upaya menguji dinamika aliran air tawar da air asin.

Pengelolaan sumberdaya air tanah pantai memerlukan suatu pengetahuan dinamika fisik dari fenomena intrusi air asin. Untuk alasan ini, yelah dibangun suatu model numeris untuk intrusi air asin yang dapat memberikan gambaran kondisi fisik sistem akuifer pantai secara komplek yang meliputi berbagai variasi keruangan dan waktu. Model yang sama telah diterapkan untuk pengelolaan air tanah di cekungan Jakarta. Sistem akuifer cekungan Jakarta memiliki tipe sistem akuifer pantai dengan lapisan akuifer yang terdiri dari lapisan akuifer taktertekan, lapisan akuifer tertekan I dan lapisan akifer tertekan II. Sumberdaya air tanah pada ketiga sistem akuifer tersebut merupakan sumberdaya air tanah yang sangat penting bagi kota Jakarta, baik untuk air minum, air untuk industri, hotel, perkantoran dan berbagai fasilitas umum lainnya. Mengingat pentingnya sumberdaya air tanah bagi Jakarta maka diperlukan suatu upaya terpadu untuk melestarikan sumberdaya air tersebut agar tetap handal dan terjaga kelestariannya dengan melakukan suatu sistem pengelolaan sumberdaya air tanah.

\subsection{Kondisi Fisik Cekungan Jakarta}

\section{Kondisi Geologi/Geomorfologi}

Geologi permukaan daerah Jakarta dan sekitarnya dibagi menjadi 6 sistem yaitu: 1 . Formasi Jatiluhur (Miosen). 2. Formasi Bojongmanik (Miosen).3. Formasi Genteng (Pliosen). 4. Formasi Vulkanik Tua (Pleistosen). 5. Formasi Vulkanik Muda (pleistosen). 6. Sedimen Aluvial.

Formasi Jatiluhur (Miosen) dapat dilihat di pegunungan sebelah tenggara cekungan Jakarta, litologi formasi ini tersusun oleh batu lempung berlapis, pasir kuarsa, dan napal. Formasi ini mengalami pemadatan sehingga bersifat sebagai batuan dasar yang impermeabel. Formasi Bojongmanik (Miosen) mempunyai tiga anggota, angota yang paling bawak susunan utama adalah batu gamping dengan selang-seling antara lempung dan pasir. Batuan umumnya keras dengan permeabilitas rendah, tetapi mengandung retakan dan lubang hasil pelarutan (solusi). Anggota kedua terdiri dari lempung, batu pasir kuarsa, batu tuf dengan kandungan fosil muluska. Batuan ini bersifat impermeabel. Anggota ke tiga terdiri dari batu pasir, yang mengandung lempung, batu pasir tuf kasar, dengan selang seling batu gamping. Batuan ini umumnya mempunyai permeabilitas rendah. Formasi Genteng (Pliosen) Letaknya di daerah Tangerang, sekaligus merupakan bagian dasar sungai Cisadane. Bagian atas formasi ini membentuk akuifer di daerah Tangerang. Formasi ini tersusun oleh batu pasir kasar tufaan, lempung, gabungan fragmen pumis.

Formasi Vulkanik Tua, Fornasi ini terbagi kedalam 4 anggota yaitu Breksi lahar (Vb), Aliran Lava Vulkanik Tua (VE), batuan Vulkanik Tua Terpropilitisasi (Vp) dan Vulkanik Tua yang sulit dibedakan (Vu). Penyebaran formasi ini sangat luas di daerah selatan, pegunungan barat dan timur. Sifat batuan permeabilitas tinggi sampai rendah. Formasi Vulkanik muda, formasi ini dikelompokkan menjadi vulkanik muda (V1), batuan vulkanik mengandung pumis ( $\mathrm{Va}$ ) dan batuan vulkanik muda (V), Batuan yang paling atas (V) terdistribusi luas dan terdiri dari lempung tufaan, pasir, konglomerat, endapan lahar, lapuk. Lapisan ini mempunyai permeabilitas tinggi dan membentuk akuifer tak tertekan.

Sedimen aluvial, sedimen aluvial di Jakarta dibagi menjadi 3 (tiga) yaitu: aluvium sungai daerah pantai (As), pematang pantai (Ap) dan 
aluvium (A1), As merupakan endapan sungai tua (purba) yang tersebar sepanjang pantai.

\section{Sistem Akuifer Jakarta}

Menurut Soekardi (1982) satuan hidrogeologi Jakarta dibagi menjadi 2 lapisan yaitu akuifer tak tertekan dan tertekan. Lapisan akuifer tak tertekan memiliki kedalaman sampai $60 \mathrm{~m}$. Lapisan ini dikelompokkan kedalam unit stratigrafi I. Lapisan ini disusun oleh litologi yang terdidi dari lempung, lempung berpasir, lempung pasir tufaan, pasir berlempung, pasir dan gravel.

Lapisan akuifer tertekan dikelompok kan menjadi 3 (tiga) grup. Pada grup I (A, B) terdiri dari lapisan akuitard I, Artetis, Akuifer artetis I dan Akuitard II. Lapisan akuifer pada grup I ini meliputi 4 (empat) satuan stratigrafi yaitu Unit II, III, IV dan V. Lapisan akuifer grup I unit II dan III ini mempunyai Litologi yang terdiri dari Lempung keras, lempung berpasir, pasir, grafel batu pasir, dan konglomerat. Unit IV dan V mempunyai litologi lempung, lempung berpasir, pasir kuarsa dan lempung keras. Lapisan akuifer grup I ini diapit oleh dua buah lapisan semi permeabel mempunyai kedalaman sampai $150 \mathrm{~m}$.

Lapisan akuifer grup II C merupakan lapisan akuifer artetis II, lapisan ini termasuk dalam unit stratigrafi VI dan VII, dengan litologi terdiri dari: lempung berpasir, pasir berlempung dengan pasir kuarsa, pasir kuarsa gravel, lempung dan lempung berpasir. Lapisan akuifer grup II C ini juga diapit oleh lapisan semi permeabel dengan kedalaman sampai $250 \mathrm{~m}$.

Lapisan akuifer grup III D terdiri dari lapisan Akuitard III dan akuifer artetis III. Lapisan grup III D ini termasuk dalam untit stratigrafi VIII dan IX dengan litologi yang terdiri dari lempung berpasir, lempung gravel, utamanya lempung, lempung pasir dengan korelasi dengan lapisan pasir. Sedimen ini mengandung konglomerat dengan sortasi bagus. Komposisi batuan terdiri dari batuan andesitik dan basaltik. Ini merupakan daerah akuifer tak tertekan yang bagus. Ap merupakan endapan pasir lepas, dengan ukuran halus, mengandung cangkang fosil. Ini termasuk akuifer tak tertekan yang permeabel dan mempunyai muka air tanah rendah. Al merupakan endapan resen, dibedakan menjadi 3 jenis yaitu aluvial pantai, aluvial sungai dan llembah aluvial. Sedimen ini terdiri dari lempung, pasir, gravel dan boulder andesit atau basalt, sifat permeabilitasnya tinggi. Sedimen aluvial lembah juga mempunyai permeabilitas tinggi.

\section{METODOLOGI}

\subsection{Pendekatan Model Matematis}

Pendekatan model matematis yang digunakan untuk menganalisa penyusupan air laut di akuifer pantai adalah model komputer quasi tiga dimensi dengan metode finite difference. Permodelan akuifer yang digunakan sebagai pendekatan adalah sharp interface, yaitu dengan menganggap adanya batas tegas yang memisahkan antara air asin dengan air tawar dalam sebuah persamaan matematis. Persamaan tersebut merupakan gabungan antara persamaan aliran air tawar dan air asin di

lapisan akuifer yang diselesaikan dengan algoritma Langrangian dan prosedur modifikasi gradien (Formulasi 1). Model intrusi air laut kemudian dibentuk atas dasar model simulasi koputer oleh Essaid et al. (1989 dan 1990) dari USGS (United State Geological Survey). Untuk model simulasi ini digunakan 5 asumsi yaitu :

1. Ketebalan daerah transisi adalah relatif kecil terhadap ketebalan akuifer, sedangkan air asin serta air tawar merupakan cairan yang immiscible (tidak bersatu) yang dipisahkan oleh daerah batas (interface).

(3)

$\mathrm{S}_{\mathrm{f}} \mathrm{B}_{\mathrm{f}} \frac{\delta \mathrm{h}_{\mathrm{f}}}{\delta \mathrm{t}}+\phi \alpha \frac{\delta \mathrm{h}_{\mathrm{f}}}{\delta \mathrm{t}}+\phi\left[\delta \frac{\delta \mathrm{h}_{\mathrm{f}}}{\delta \mathrm{t}}-(1+\delta) \frac{\delta \mathrm{h}_{\mathrm{s}}}{\delta \mathrm{t}}\right]=\ldots \ldots \ldots \ldots \ldots$. Formulasi 1

(5) (6)

$\frac{\delta}{\delta x}\left[\mathrm{~B}_{\mathrm{f}} \mathrm{K}_{\mathrm{fx}} \frac{\delta \mathrm{h}_{\mathrm{f}}}{\delta \mathrm{x}}\right]+\frac{\delta}{\delta \mathrm{y}}\left[\mathrm{B}_{\mathrm{f}} \mathrm{K}_{\mathrm{fy}} \frac{\delta \mathrm{h}_{\mathrm{f}}}{\delta \mathrm{y}}\right]+\mathrm{Q}_{\mathrm{f}}+\mathrm{Q}_{\mathrm{ff}}$ 
$\mathrm{S}_{\mathrm{s}} \mathrm{B}_{\mathrm{S}} \frac{\delta \mathrm{h}_{\mathrm{s}}}{\delta_{\mathrm{t}}}+\phi\left[(1+\delta) \frac{\delta \mathrm{h}_{\mathrm{s}}}{\delta_{\mathrm{t}}}-\delta \frac{\delta \mathrm{h}_{\mathrm{f}}}{\delta \mathrm{t}}\right]=\frac{\delta}{\delta \mathrm{x}}\left[\mathrm{B}_{\mathrm{s}} \mathrm{K}_{\mathrm{sx}} \frac{\delta \mathrm{h}_{\mathrm{s}}}{\delta \mathrm{x}}\right]+\frac{\delta}{\delta \delta_{\mathrm{y}}}\left[\mathrm{B}_{\mathrm{s}} \mathrm{K}_{\mathrm{sy}} \frac{\delta \mathrm{h}_{\mathrm{s}}}{\delta \mathrm{y}}\right]+\mathrm{Q}_{\mathrm{s}}+\mathrm{Q}_{\mathrm{ls}}$

Keterangan :

$\mathrm{K}_{\mathrm{fx}}=$ hidraulik konduktivitas air tawar arah $\mathrm{x}\left(\mathrm{LT}^{-1}\right)$

$\mathrm{K}_{\mathrm{sx}}=$ hidraulik konduktivitas air asin $\operatorname{arah} \times\left(\mathrm{LT}^{-1}\right)$

$\mathrm{K}_{\mathrm{fy}}=$ hidraulik konduktivitas air tawar $\operatorname{arah} \times\left(\mathrm{LT}^{-1}\right)$

$\mathrm{K}_{\mathrm{sy}}=$ hidraulik konduktivitas air asin $\operatorname{arah} \times\left(\mathrm{LT}^{-1}\right)$

$\varnothing \quad=$ Efektif porositas

$\mathrm{Q}_{\mathrm{f}}, \mathrm{Q}_{\mathrm{s}}=$ sumber/penampungan air tawar/asin $\left(\mathrm{LT}^{-1}\right)$

$\mathrm{Q}_{\text {lf }} \mathrm{Q}_{\mathrm{ls}}=$ Kebocoran air tawar/asin ( $\left.\mathrm{LT}^{-1}\right)$

(1) = Formulasi ini mewakili perubahan elastic storage dalam setiap domain

(2) = Formulasi ini mewakili perubahan storage air tawar karena aliran di dalam akuifer air tanah dangkal

(3) = Formulasi ini mewakili perubahan storage dalam setiap domain karena pergerakan dari interface

(4) = Formulasi ini mewakili perbedaan fluk dalam arah sumbu $\mathrm{x}$ dan $\mathrm{y}$

(5) = Formulasi ini mewakili sources (recharge) dan sinks (pumping) ke dalam akuifer

(6) = Formulasi ini mewakili nilai kebocoran akuitard

2. Untuk lapisan akuifer majemuk, setiap akuifer dipisahkan oleh lapisan tidak tertekan atau akuitard yang berisi media berongga yang bervariasi.

3. Kebocoran aliran ke dan dari akuifer terjadi secara vertikal dan dalam kondisi statis.

4. Pendekatan Dupoit diterapkan dalam sistem akuifer.

5. Konduktivitas hidrolik dan koefisien storage tidak berubah secara vertikal.

Model matematis untuk proses optimisasi dapat dilihat pada persamaan Formulasi 2.

Model optimisasi ini kemudian dikembang kan oleh Finney dan Willis (1989) dan diterjemahkan ke dalam bahasa komputer dengan algoritma BOX. Model optimisasi ini kemudian digabungkan dengan model simulasi Essaid (1989) sehingga menjadi model optimisasi pengelolaan air tanah.

$$
\begin{aligned}
& \min J=\sum_{t=1}^{N} L t(X t, P t, t) \ldots \ldots . . \text { Formulasi } 2 \\
& X t+1=T(X t, P t, t) \\
& t=1,2,3 \ldots \ldots \ldots \ldots ., N \\
& G(X t, P t, t) \leq \bar{G}(X t, P t, t) \\
& t=1,2,3 \ldots \ldots \ldots \ldots ., N
\end{aligned}
$$

$$
\begin{aligned}
& X t \in R^{n} \\
& P t \in R^{m}
\end{aligned}
$$

Keterangan :

$T \quad=$ Fungsi yang mengontrol sistem akuifer dari $X_{t}$ ke $X_{t+1}$ dimana variabel penentu $P_{t}$ adalah fungsi dari variabel $h_{f}, h_{s}$ dan $z^{t}$

$G \quad=$ Satu kelompok kendala dan kontrol pada periode perencanaan $t$ untuk meminimumkan penurunan muka air tanah yang berlebihan atau efek interferensi sumur. Dapat dieksperesikan juga sebagian batas pemompaan air tanah, atau untuk memenuhi kebutuhan air atau imbuhan.

$L_{t} \quad=$ Fungsional objektif dalam periode perencanaan $t$

$X_{t}=$ Vektor tertentu pada permulaan periode perencanaan $t$

$P_{t} \quad=$ Vektor kontrol yang menentukan pemompaan atau imbuhan yang terjadi selama periode perencanaan $t$.

\subsection{Pengoperasian Model Simulasi dan Optimisasi}

Dalam pengoperasian model secara garis besar dapat dinyatakan bahwa simulasi model akan mengolah tiga kelompok data masukan yaitu : pemompaan, parameter akuifer dan imbuhan alami. Hasil simulasi akan dioptimisasikan dengan 
pemompaan sebagai faktor penentu yang dapat diubah-ubah untuk mencapai nilai tujuan (volume air asin minimum). Dalam hal ini digunakan model komputer SHARP yang dapat membuat simulasi aliran air tanah dan model komputer BOX yang digunakan untuk optimisasi dari hasil simulasi tersebut. Diagram alir pengerjaan Model Simulasi dan Optimisasi dapat dilihat pada Gambar 4.

Sepuluh tahun lalu untuk pengoperasian model ini membutuhkan komputer SUN-4 (di BPP Teknologi) dan waktu yang diperlukan berkisar 26 menit (simulasi) dan 6 Jam 40 menit (optimisasi). Sedangkan di IBM-3090 (IPTN, Bandung) waktu yang diperlukan untuk proses simulasi adalah 23 detik dan optimisasi 7 menit. Dengan adanya pengoperasian sistem UNIX pada PC, dan perkembangan mikroprosesor yang begitu cepat, sekarang program ini dapat dijalankan pada komputer PC atau notebook.

\subsection{Data Input Model}

Data masukan memegang peranan penting dari suatu model simulasi. Bagaimanapun baiknya suatu model simulasi apabila tidak ditunjang oleh data masukan yang tepat akan mengakibatkan hasil simulasi menjadi sulit dimengerti dan tidak mempunyai kecenderungan yang sama dengan kondisi yang sebenarnya dilapangan. Dalam model simulasi air tanah Jakarta ini, data masukan yang digunakan adalah :

a. Rancangan Blok dan Kondisi Daerah Batas Daerah penelitian meliputi wilayah Jabotabek dengan luas $4800 \mathrm{~km} 2$. Daerah ini dibagi menjadi 12 x 16 blok dengan luas tiap blok 25 $\mathrm{km} 2$. Kondisi batas daerah di sebelah selatan, tenggara dan timur adalah singkapan batuan yang berumur tersier yang dianggap sebagai daerah kedap air. Daerah batas ini dalam model komputer diberi kode "O" sedangkan daerah yang lulus air atau titik aktif, dalam model komputer diberi kode "1". Daerah yang diasumsikan mempunyai tinggi tekan air tanah konstan terletak di sebelah utara Bogor, batas timur, batas barat dan di derah utara sepanjang pesisir dekat pantai. Daerah ini dalam input model diberi tanda "_" pada koefisien storagenya.

b. Parameter Akuifer :

- Konduktivitas Hidrolik (Kx dan Ky)

Data Kx dan Ky di dapat dari hasil penelitian terdahulu antara lain dari Schmidt \& Haryadi (1986), CRDB (1987) dan Djaendi dkk. (1985). Nilai Kx untuk daerah Jakarta utara antara $6,5 \times 10^{-4}$ s.d. $2,9 \mathrm{~m} /$ hari sedangkan untuk daerah Jakarta bagian tengah berkisar 1,32 x 10-4 s.d. 2,3 $\mathrm{m} /$ hari dan untuk daerah Jakarta bagian selatan nilainya berkisar antara 1,4 $x$ 10-4 s.d. $1,1 \mathrm{~m} / \mathrm{dtk}$. Besarnya nilai $\mathrm{Ky}$ adalah $1 / 100$ dari nilai $\mathrm{Kx}$.

- Transmisivitas (T)

Transmisivitas (T) untuk seluruh lapisan kuarter dengan ketebalan $250 \mathrm{~m}$ adalah kira-kira $250 \mathrm{~m} /$ hari di dekat pantai dan di daerah selatan meningkat sampai 500 $\mathrm{m} /$ hari. Sedangkan menurut Joice dan Kamata (1987) transmisivitas akuifer I berkisar antara $326 \mathrm{~m} /$ hari dan 9,6 m/hari dengan rata-rata $120 \mathrm{~m} /$ hari, akuifer II berkisar antara $300 \mathrm{~m} /$ hari dan $31 \mathrm{~m} /$ hari dengan rata-rata $142 \mathrm{~m} /$ hari.

- Koefisien Storage (STORF dan STORS)

Koefisien daya simpan air tawar pada akuifer dalam (tertekan) atau STORF adalah berkisar antara $10^{-2}$ dan $10^{-6}$ (Djaendi dkk, 1985). Nilai koefisien daya simpan air untuk akuifer tertekan diasumsikan homogen yaitu 10-6 sedangkan untuk akuifer tertekan II berkisar antara $1 \times 10^{-4}-3,6 \times 10^{-3}$ dan untuk akuifer tertekan II berkisar antara $1 \mathrm{x}$ $10^{-4}-3,6 \times 10^{-3}$ dan untuk akuifer dangkal sebesar 0,2 . Koefisien daya simpan air asin atau STORS untuk air tanah tertekan I diasumsikan homogen yaitu sebesar $1 \mathrm{x}$ $10^{-4}$, air tertekan II diasumsikan $1 \times 10^{-18}$ dan untuk akuifer dangkal $1 \times 10^{-20}$.

- Porositas (POR)

Nilai porositas untuk model simulasi ini masih diasumsikan homogen terutama untuk akuifer tertekan I dan II (0,15 dan $0,05 \%)$ sedangkan porositas akuifer dangkal berkisar antara $5-15 \%$. Nilai porositas yang dimaksud disini adalah porositas efektif batuan.

- Kebocoran Akuitard (Aquitard Leakage, $A Q L)$

Kebocoran Akuitard sulit ditentukan secara pasti dilapangan. Nilai kebocoran akuitard untuk akuitard I masih diasumsikan homogen yaitu sebesar $1,9 \times 10^{-10} \mathrm{~m} / \mathrm{dtk}$ dan akuitard II sebesar $1 \times 10^{-10} \mathrm{~m} / \mathrm{dtk}$.

- Tebal Akuifer (THCK) 
Ketebalan akuifer air tanah Jakarta sebenarnya sangat bervariasi, baik dari arah selatan ke utara maupun dari barat ke timur. Dalam model simulasi ini tebal akuifer diasumsikan homogen dan lapisan akuifer dikelompokkan atas 3 bagian yaitu : akuifer tertekan I (140 s/d 250 meter) tebalnya 90 meter, akuifer teretkan II (40 s/d 140 meter) tebalnya 84 meter dan akuifer bebas III ( $0 \mathrm{~s} / \mathrm{d} 40$ meter) tebalnya 40 meter. Tebal akuitard I rata-rata 19 meter dan tebal akuitard II adalah 15 meter.

\section{- Elevasi Akuifer (ZBOT)}

Elevasi akuifer di alam sebenarnya sangat bervariasi (akuifer bergelombang), tetapi dalam model ini akuifer dangkal diasumsikan sebesar -40 meter, akuifer tertekan I adalah -140 meter dan akuifer tertekan II adalah -250 meter dari bawah muka laut (bml). Pada program simulasi sudah dipersiapkan untuk akuifer bergelombang tetapi karena keterbatasan data untuk saat ini masih masih digunakan ZBOT homogen,

\section{- Elevasi Interface (ZINT)}

Elevasi interface adalah ketinggian titik pertemuan antara air laut dan air tawar. Data mengenai ketinggian interface wilayah Jakarta di dapat dari studi Penyusupan Air Laut di Wilayah DKI Jakarta 1989. Batas bagian bawah interface dipakai bagian bawah dari elevasi dasar dari masing-masing akuifer.

- Tinggi Tekan Air (PHIF)

Data tinggi tekan air tanah selalu dimonitor sejak tahun 1980 baik untuk air tanah dangkal, tertekan I dan II. Untuk pengkalibrasian program simulasi digunakan data PHIF tahun 1987 karena data pada tahun tersebut adalah yang paling lengkap.

\section{- Imbuhan Alami (RECH)}

Dalam model ini nilai imbuhan alami hanya terjadi pada akuifer bebas dari nilainya ditentukan dari hasil studi DGTL dan INDEC et al. Pada beberapa tempat dihitung berdasarkan jenis batuan, tumbuhan penutup yang tumbuh di atasnya, curah hujan dan fluktuasi air tanah dangkal.

\subsection{Jumlah Pemompaan}

Jumlah pemompaan air tanah Jkaarta hingga saat ini sulit ditentukan secara pasti. Data distribusi pemompaan dan prosentase pemakaian tiap wilayah diolah dari data PAM DKI Jakarta sedangkan jumlah pemompaan totalnya ditentukan berdasarkan kebutuhan air tanah per kapita penduduk DKI Jkarta. Dengan melakukan simulasi Model Air Tanah Jakarta dapat diketahui berapa besar pemompaan air tanah yang sebenarnya untuk setiap akuifer dan setiap daerah.

\section{APLIKASI MODEL}

Model simulasi dan optimisasi air tanah telah diaplikasikan di Cekungan Jakarta. Ada beberapa alasan yang menyebabkan model tersebut diterapkan di Cekungan Jakarta antara lain:

1. Sistem akuifer Cekungan Jakarta merupakan sistem akuifer tipe pantai.

2. Data tersedia cukup banyak baik itu data pemompaan, pemboran maupun data hidrogeologi lainnya. Pencatatan data hidrogeologi sudah dimulai sejak tahun 1980.

3. Penelitian yang menyangkut kondisi air tanah Jakarta sudah banyak dilakukan dan pada umumnya disimpulkan bahwa kondisi air tanah Jakarta semakin turun baik dari segi kualitas dan kuantitas.

4. Kedudukan ibu kota Jakarta sangat strategis dan penting, menyangkut berbagai kepentingan.

\subsection{Hasil Simulasi}

Simulasi dengan model komputer SHARP telah dilaksanakan berulang kali bersamaan dengan pelaksanaan kalibrasi model dan validasi data. Proses kalibrasi dilakukan terhadap data tahun 1987. Pemompaan yang dilakukan sebesar $7,9 \mathrm{~m} 3 / \mathrm{dt}$. Dari hasil simulasi yang dapat dilihat adalah tinggi tekan air tawar, pola depresi atau pola penurunan muka air tanah yang terjadi akibat pemompaan, gambaran pergerakan interface air asin dan air tawar dan peta penyusupan air laut. Hasil simulasi memang tidak dapat $100 \%$ sama, hal yang menjadi perhatian utama adalah hasil simulasi menunjukkan kecenderungan akibat yang sama dari pengambilan air tanah yang berlebihan di daerah Jakarta.

Hasil proses simulasi air tanah Jakarta tahun 1987 diketahui bahwa pengambilan air tanah sebesar 7,9 m3/detik dapat mengakibatkan : Lapisan I menunjukkan ada dua depresi disebelah 
barat (,-18,7 M, Grogol) dan Timur $(-13,7 \mathrm{M}$, Pulogadung) sedangkan pada peta dasar tahun 1987 (Gambar 4) menunjukkan satu depresi. Pada lapisan akuifer II secara umum menunjukkan kecenderungan yang sama dengan peta dasar. Pada lapisan akuifer III depresi yang terjadi hampir menyerupai peta dasar yaitu di bagian barat $(-1 \mathrm{~m}$, Cengkareng) dan di bagian tengah (-1 $\mathrm{m}$, Jakarta Pusat) sedangkan pada peta dasar terjadi di sebelah barat dan di timur.

Dari hasil simulasi 1987, 1990, 2000, 2015 dapat terlihat bagaimana perubahan kondisi air tanah dari tahun ke tahun.Dari hasil simulasi tersebut dapat pula diperlihatkan bahwa akibat naiknya laju pemompaan akan terjadi penurunan air tanah semakin dalam dari tahun ke tahun,dan penyusupan air laut yang semakin jauh ke arah daratan. "Cone depresi" pada tempat-tempat yang besar pengambilan air tanahnya sulit untuk dihindari karena kecepatan pulih muka air tanah sangat rendah dibanding laju pengambilannya.Untuk menghindari kejadian ini maka perlu diadakan pengaturan lokasi pemompaan air tanah disesuaikan dengan kemampuan daerahnya.

\subsection{Hasil Optimisasi}

Proses optimisasi dilakukan agar potensi air tanah yang terbatas ini dapat dimanfaatkan seoptimal mungkin tanpa mengakibatkan penyusupan air laut lebih jauh ke arah darat. Sedangkanjarak penyusupan yang diinginkan,sebenarnya dapat pula ditentukan dengan menentukan batasnya dalam input model. Proses optimisasi dilakukan untuk tahun 1987,1990,2000 dan 2015 sesuai dengan proses simulasi agar hasilnnya dapat dibandingkan. Proses optimisasi berusaha mendapatkan pemompaan optimal untuk setiap setiap tahun yang diprediksi. Pemompaan optimal sering juga diimbangi oleh imbuhan buatan yang optimal. Batas maksimal laju imbuhan buatan dapat diatur sedemikian rupa sehingga kecepatannya sama dengan kecepatan resapan air tanah dengan harapan agar nilai imbuhan buatan optimalnya tidak terlalu besar. Walaupun untuk mengadakan peresapan pada akuifer dalam tentu merupakan persoalan yang sulit terutama menyangkut biaya, pengadaan air baku dan teknis.

Program optimisasi ini dapat diatur agar imbuhan buatan dalam akuifer dalam (I dan II) ditiadakan sehingga yang ada hanya imbuhan. Tanda minus menunjukkan imbuhan. Dengan perhitungan sederhana dan mengenal sifat-sifat wilayah, maka dapat dihitung jumlah sumur buatan pada air tanah dangkal. Pengaturan ini akan menghasilkan "output" imbuhan buatan optimal yang lebih mungkin untuk dilaksanakan di lapangan, baik teknis maupun ekonomis. Lokasi dari imbuhan buatan disesuaikan dengan kebijakan pengembangan kota dan tata guna lahan yang ada. Dengan demikian informasi besarnya imbuhan buatan optimal yang akan diberikan oleh model optimisasi akan sesuai lokasinya dengan apa yang seharusnya dilakukan.

Dari hasil optimisasi tahun 1987, 1990, 2000 dan 2015 kemudian diringkas seperti Tabel 2. Proses optimisasi (historis) tanpa dilakukan imbuhan buatan menunjukkan nilai obyektif ("Objective value") yang lebih tinggi dibandingkan dengan proses opimisasi dengan melakukan imbuhan buatan. Nilai obyektif ini mencerminkan volume air laut yang masuk ke dalam akuifer air tawar. Peningkatan nilai obyektif menunjukkan adanya intrusi air laut. Dari keadaan itu dapat disimpulkan bahwa imbuhan buatan dapat menahan laju penyusupan air laut. Pada tingkat pemompaan tertentu proses optimisasi dapat menjadi tidak efektif lagi sebab terlalu banyak imbuhan buatan yang harus dilakukan sehingga dalam menafsirkan hasil optimisasi ini perlu hatihati.

Kondisi saat ini menunjukkan harapan yang sebaliknya, hasil penelitian Rahardjo dan Saraswati (2002), di daerah Depok menunjukkan bahwa dengan bertambahnya penduduk dan luas wilayah tutupan imbuhan air tanah menurun dari tahun ke tahun. Kondisi ini tentu sangat memprihatinkan, dalam jangka panjang akan berpengaruh terhadap pengisian air tanah Jakarta. Oleh karena itu dibutuhkan kebijakan real yang dapat diterapkan di lapangan untuk meningkatkan nilai imbuhan air tanah, terutama di daerah yang sudah direkomendasikan sebagai daerah resapan. Konstribusi silang sebaiknya juga dilakukan dari wilayah pemakai ke wilayah pemasok (utara ke selatan).

\subsection{Peta Imbuhan Air Tanah}

Salah satu keunggulan program ini adalah munculnya rekomendasi wilayah yang harus dilakukan imbuhan (bisa secara alami atau buatan), sesuai dengan sifat fisik akuifer yang dinformasikan kedalam data input. Angka yang ditunjukan dalam peta (Gambar 5, 6 dan 7) adalah besarnya imbuhan yang harus dilakukan didaerah tersebut (dalam satuan m3/detik).

resapan atau luasan waduk yang harus dibangun di wilayah tersebut agar resapan airnya. 
Besarnya imbuhan buatan yang harus dimasukkan kembali kedalam akuifer dangkal untuk daerah seluas $25 \mathrm{~km} 2$ berkisar antara 1.082.419-54.120.960 $\mathrm{m} 3 /$ tahun atau antara 1,08 - 54,12 m3/tahun/m2. Lokasi imbuhan buatan dapat dilihat pada Peta Lokasi Imbuhan Buatan Berdasarkan Hasil Optimisasi Pengelolaan Air Tanah. Jika diasumsikan 1 (satu) sumur resapan dengan diameter 0,8 meter, lebar bidang resapan 1 meter pada tanah dengan permeabilitas rendah $(0,00105 \mathrm{~m} /$ hari $)$, maka kapasitas sumur resapan adalah 0,592 $\mathrm{m} 3 /$ tahun/unit. Dengan demikian untuk daerah Jakarta dan sekitarnya dibutuhkan kurang lebih 2 juta sumur resapan.

Mengingat jumlah sumur resapan demikian besar, maka dibutuhkan dana yang sangat besar untuk melestarikan air tanah Jakarta, agar tetap lestari. Sosialisasi sumur resapan sudah dilakukan oleh Pemda DKI, demikian juga dengan percontohannya. Dalam kondisi krisis ekonomi, sebaiknya program pembuatan sumur resapan, dikaitkan dengan program bantuan ekonomi untuk memperkuat jaring pengaman sosial, dengan cara memperbaiki lingkungan dan meningkatkan kesejahteraan masyarakat.

\section{REKOMENDASI}

1. Air tanah merupakan sumber yang berharga dalam hal mensuplai kebutuhan air JABOTABEK. Oleh karena itu, penanganan yang tepat dari cekungan air tanah harus dijalankan dalam sudut pandang konservasi dan pengembangan.

2. Keduanya program jangka panjang dan kegiatan jangka pendek direkomendasikan untuk mengelola dan mengembangkan sumber air tanah di Jabotabek. Pengelolaan ini harus diterapkan dengan mengutamakan daerah barat dan selatan-barat (barat-daya) Jakarta, dimana suplai air permukaan yang tidak akan tersedia

3. Program jangka panjang yang dibutuhkan untuk mendapatkan data yang diperlukan untuk mengelola sumber daya meliputi :

a. Konsolidasi dari inventarisasi sumur;

b. Program pemantauan permukaan air yang lebih memadai;

c. Mempertahankan program pemantauan kualitas air yang ada Rancangan dan pembangunan suplai air alternatif untuk menggantikan pemompaan berlebihan dari sumur bor di area Jakarta Utara. d. Mengatur pemompaan dan mengurangi pembuangan di Jakarta ke laju imbuhan;

e. Melaksanakan pengukuran untuk melindungi dan meningkatkan imbuhan air tanah.

4. Kegiatan jangka pendek juga dibituhkan untuk mendapatkan data yang diperlukan untuk pengelolaan akuifer cekungan air tanah Jakarta, meliputi :

a. Pengumpulan dan evaluasi data pada sumur bor dalam

b. Mengajak ahli yang sudah dikenal ke 'land subsidence' untuk meng-evaluasi bukti yang ada

c. Melaksanakan geodetik levelling yang teliti dan menetapkan 'benchmark' (titik acuan) untuk membantu studi land subsidence;

d. Evaluasi kemungkinan secara buatan untuk meningkatkan imbuhan air tanah seperti situ-situ, sumur imbuhan dan perencanaan kota;

e. Lakukan kembali pengoperasian model air tanah untuk menyediakan data tambahan untuk perencanaan pengembangan air tanah.

5. Pemberian imbuhan air pada sistem akuifer dengan mengikuti skenario yang dikeluarkan oleh Model Optimisasi Pengelolaan Air Tanah akan dapat dipakai sebagai bahan masukan dalam pengelolaan air tanah.

\section{DAFTAR PUSTAKA}

1. Cordery,I. 1976, Evaluation And Improvement of Quality Characteristics of Urban Stormwater. New South Wales, Australia, The University of New South Wales School Of Civil Engineering.

2. CRBD, 1987, Cisadane River Basin Development Feasability Study, Directorate General of Water Resources Development, Jakarta, Vol. 1-12.

3. Dadi Harnandi, Dipl. H. dan Wawan Sungkawan, Dipl. H. 1988, Laporan Hasil Tinjauan Sumur Pantau di Wilayah Jabotabek Periode Agustus-November 1988, Dit. Jend. Geologi dan Sumber Daya Mineral, Dit. GTL, Sub. Dit. Hidrogeologi, Bandung.

4. DEG, 1985, Groundwater Geophysics, Vol. 2-3 (1984), GHAG-CTA 40, HAG 64, $64.1,64.2,65,85,86,87$, DEG, Bandung. 
5. Deny, J. 1994. Kelestarian Imbuhan Air Tanah Dengan Memanfaatkan Teknologi Konservasi Air Tanah. Dalam Seminar Memasyarakatkan Penggunaan Air tanah di Wilayah Jakarta Seefisien Mungkin. Jakarta, 26 Oktober 1994.

6. DGTL, 1988, Studi Intrusi Penyusupan Air Laut di Wilayah DKI Jakarta, GTL dan PAM JAYA, Bandung.

7. Djaendi, 1985, Studi Air Tanah Jakarta, Vol.4-6 Evaluasi, Uji Pemompaan Sumur Pengamat Kuningan, Walang Baru, Tongkol, Cilodok dan Cipondok, GHAG CTA 40, HAG 95, DEG, Bandung.

8. Djaeni, G. Kohler dan B. Soefner, Jakarta Ground Water Study, Vol 6-2, Piezometric Heads of The Unconfined Aquifer System 1984-1985, GHAG CTA 40, HSG 103, DEG, Bandung.

9. Djoko Warsito, 1984, Studi Air Tanah Jakarta, Vol. 4, Topografi dan Geologi Daerah Jakarta-Bogor termasuk Kompilasi Data Aliran Permukaan, GHAG-CTA 40, HAG 76, DEG, Bandung.

10. Esaid, Hedeff I., 1989, The Computer Medel SHARP: A Quasi-Three Dimensional Finite-Difference Model to Simulate Fresh Water and Saltwater Flow in Layered Coastal Aquifer Systems, USGS, Manlo Park, California.

11. Esaid, Hedeff, I., 1990, The Computer Model SHARP: A Quasi-Three Dimensional Finite-Difference Medol ti Simulate Fresh-Water and Saltwater Flow in Layered Coastal Aquifer Systems, USGS, Manlo Park, California.

12. Fauzi Maimun dan Maridjo, 1985, Jakarta Grounwater Study, Vol. 6-1, Location and Topographic Elevation of DEG Monitoring Wells in the Jakarta-Bogor Area, GHAG CTA 40, HAG 94, DEG, Bandung.

13. Finney, B. A., Samsuhadi dan Willis,R., Groundwater Management in The Jakarta basin, 1989.

14. Haryadi Tirtomihardjo, 1985, Studi Air Tanah Jakarta, Vol 6-2, Air Sungai di Daerah Cekungan Jakarta, GHAG-CTA 40, HAG 114, DEG, Bandung.

15. Haryoto, I, dkk. 1992. Optimisasi, Studi Model Optimisasi Pengelolaan Air Tanah Jakarta. Jakarta. Direktorat Pengkajian Sistem, Kedeputian Bidang Analisis Sistem, Badan Pengkajian dan Penerapan Teknologi.
16. Haryoto. I, Herlambang. A, Haryadi. R, 1996, Upaya Penanggulangan Banjir di Jakarta, disampaikan dalam Seminar Airborne Digital Multispektral Video dan Rancang Bangun Sumur Resapan Untuk Mengatasi Banjir Jakarta, Tanggal 12 Nopember 1996

17. Herlambang, Arie, dkk, 1989, Data Base Air Tanah Jakarta, Studi Optimisasi Pengelolaan Air Tanah Jakarta, Dit P.S, Dep. Analisa Sistem, BPPT, Jakarta.

18. Herlambang, Arie, dan Hernaningsih, Tatik, 1991, Model Simulasi dan Optimalisasi Pengelolaan Air Tanah Jakarta, Seminar Pengembangan Air Tanah, PPS Keairan, Teknik Sipil Universitas Trisakti.

19. Herlambang, Arie, dkk, 1990, Simulasi dan Kalibrasi, Studi Optimisasi Pengelolaan Air Tanah Jakarta, Dit P.S, Dep. Analisa Sistem, BPPT, Jakarta

20. Herlambang, Arie, dkk. 1991. Simulasi dan Kalibrasi, Studi Model Optimisasi Pengelolaan Air Tanah Jakarta. Jakarta. Direktorat Pengkajian Sistem, Kedeputian Bidang Analisis Sistem, Badan Pengkajian dan Penerapan Teknologi.

21. M. Hobler, 1985, Studi Air Tanah Jakarta, Vol 6-2, Air Sungai di Daerah Cekungan Jakarta, GHAG-CTA 40, HAG 96, DEG, Bandung.

22. PAM JAYA, 1981, Pengumpulan dan Kompilasi Data PAM dalam Bentuk Bank Data (Ilustrasi, Tabel, Grafik, Laporan), Vol 11, Sektor Water Supply dan Resources, Rencana Induk Pembangunan DKI 1985-2005.

23. Pemerintah Daerah Khusus Ibukota Jakarta, Brosur, Sumur Resapan Buatan Air Hujan. Jakarta. Dinas Pertambangan DKI.

24. Rahardjo dan Saraswati (2002), Simulasi Pengimbuhan Air Tanah Dangkal di Depok, Sains Indonesia, 7(1):31-36.

25. Soki Yamamoto, Prof. Dr., 1972, Geohydrologic Investigation for Municipal Water Supply of City of Jakarta, Nihon Suido Consultants Co, Ltd, Tokyo.

26. Sunjoto. 1992. Brosur Sistem Drainase Air Hujan Berwawasan Lingkungan. Yogyakarta. Fakultas Teknik Universitas Gadjah Mada. 
Tabel 1. Prediksi Beban Pengambilan Air Tanah Di Wilayah Jakarta (m3/hari/km2)

\begin{tabular}{|l|r|r|r|}
\hline \multicolumn{1}{|c|}{ Wilayah } & $\begin{array}{c}\text { Prediksi Pengambilan } \\
\text { Air Tanah (m3/hari) }\end{array}$ & Luas (km2) & $\begin{array}{c}\text { Beban } \\
(\mathrm{m} 3 / \text { hari/km2) }\end{array}$ \\
\hline Jakarta Pusat & $482,595.13$ & 54.46 & $8,861.46$ \\
\cline { 1 - 2 } Jakarta Barat & $604,211.67$ & 131.45 & $4,596.51$ \\
\cline { 1 - 2 } Jakarta Selatan & $342,049.82$ & 146.84 & $2,329.40$ \\
\cline { 1 - 2 } Jakarta Timur & $345,617.21$ & 178.07 & $1,940.91$ \\
\cline { 1 - 2 } Jakarta Utara & $130,991.77$ & 139.58 & 938.47 \\
\hline
\end{tabular}

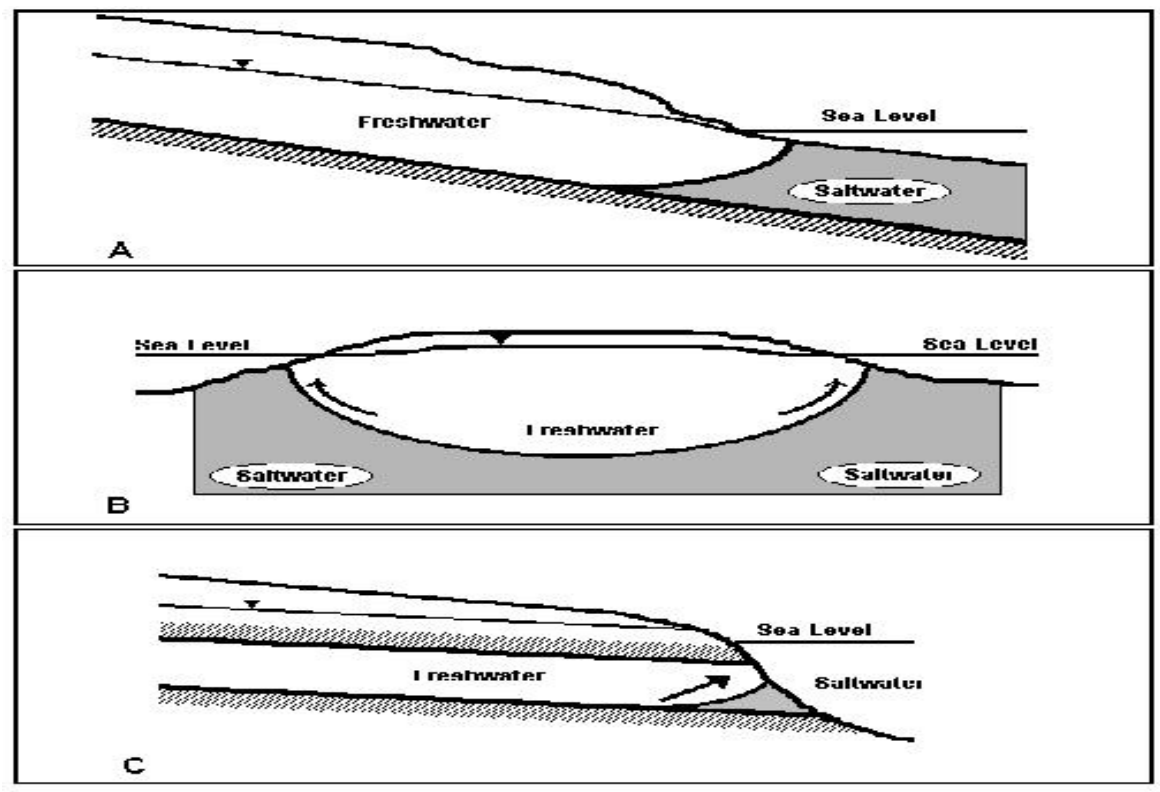

Gambar 1. Contoh Suatu Kondisi Hidrogeologi Dalam Akuifer Pantai. (A). Akuifer Tak tertekan Dengan Lapisan Dasar Impermeabel, (B). Akuifer tak Tertekan Pulau Dengan Dasar Bebas, (C). Akuifer Tertekan. 


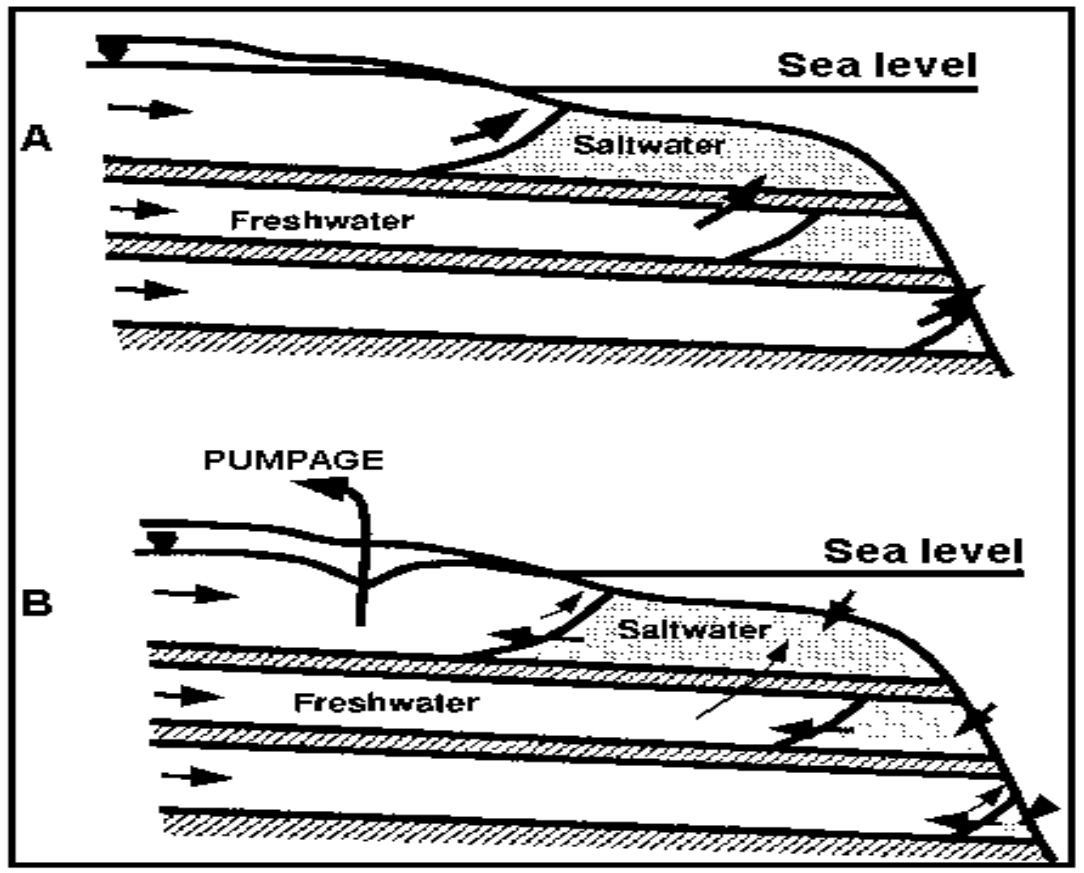

Gambar 2. Potongan Melintang Yang Ideal Suatu Sistem Akuifer Pantai

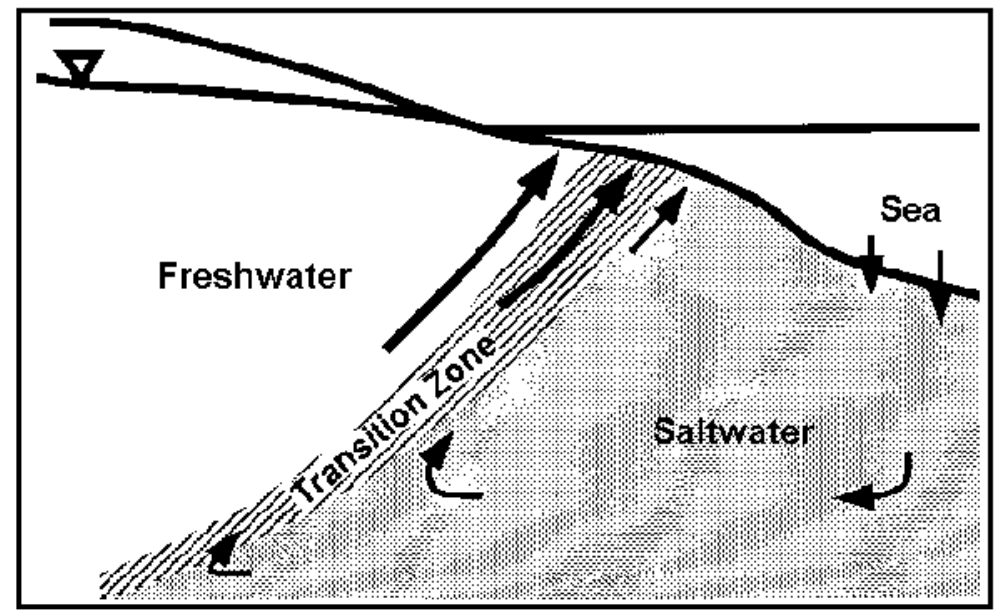

Gambar 3. Sirkulasi Air Asin Dari Laut Menuju Daerah Transisi dan Kembali Ke Laut Pada Daerah Interface (Zone Transisi) 


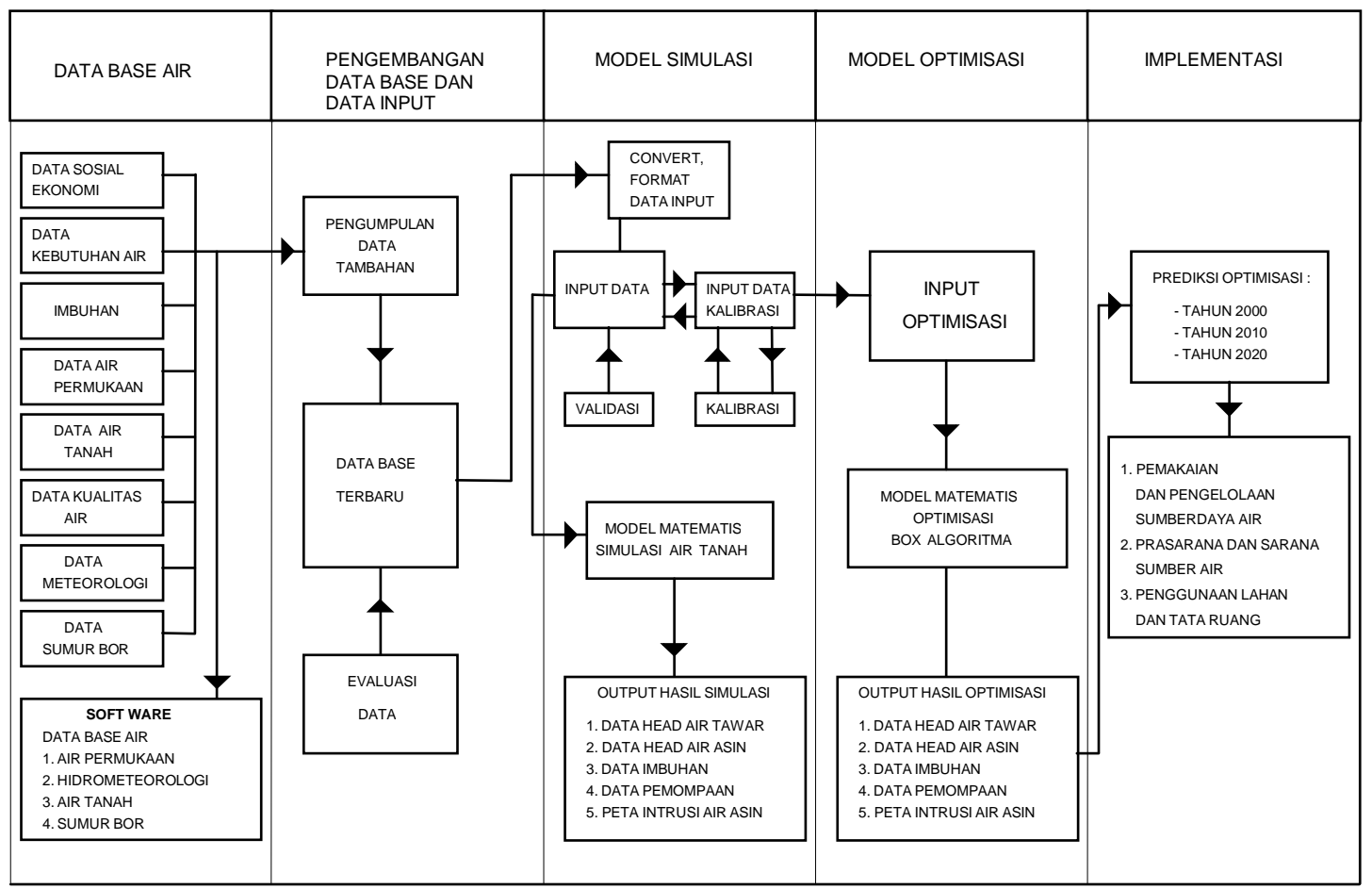

Gambar 4. Diagram alir pengerjaan Model Simulasi Dan Optimisasi

Tabel 2. Hasil Proses Optimisasi

\begin{tabular}{|c|c|c|c|c|c|c|}
\hline Tahun & $\begin{array}{l}\text { Pemompaan } \\
\text { ( } \mathrm{m}^{3} / \text { detik) }\end{array}$ & Keterangan & $\begin{array}{l}\text { Akuifer } \\
\text { Dangkal } \\
\text { (m³/detik) }\end{array}$ & $\begin{array}{l}\text { Akuifer } \\
\text { Dalam I } \\
\text { (m³/detik) }\end{array}$ & $\begin{array}{l}\text { Akuifer } \\
\text { Dalam II } \\
\text { (m³/detik) }\end{array}$ & $\begin{array}{l}\text { Nilai Objektif } \\
\left(\mathrm{m}^{3} / \text { detik }\right)\end{array}$ \\
\hline \multirow[t]{4}{*}{1987} & 7,9 & $\begin{array}{l}\text { Pemompaan } \\
\text { Historis }\end{array}$ & 3,87 & 2,05 & 1,91 & 2,94 \\
\hline & & $\begin{array}{l}\text { Pemompaan } \\
\text { Optimal }\end{array}$ & 4,45 & 2,18 & 2,27 & 2,90 \\
\hline & & Imbuhan Buatan & 0,21 & 0,01 & 0,05 & \\
\hline & & Imbuhan Alami & 26,18 & 0,00 & 0,00 & \\
\hline \multirow[t]{4}{*}{1990} & 8,1 & $\begin{array}{l}\text { Pemompaan } \\
\text { Historis }\end{array}$ & 3,96 & 2,09 & 1,96 & 2,94 \\
\hline & & $\begin{array}{l}\text { Pemompaan } \\
\text { Optimal }\end{array}$ & 4,55 & 2,33 & 2,32 & 2,93 \\
\hline & & Imbuhan Buatan & 0,24 & 0,04 & 0,08 & \\
\hline & & Imbuhan Alami & 26,18 & 0,00 & 0,00 & \\
\hline \multirow[t]{4}{*}{2000} & 9,6 & $\begin{array}{l}\text { Pemompaan } \\
\text { Historis }\end{array}$ & 4,48 & 2,92 & 1,79 & 2,95 \\
\hline & & $\begin{array}{l}\text { Pemompaan } \\
\text { Optimal }\end{array}$ & 4,69 & 2,49 & 2,32 & 2,93 \\
\hline & & Imbuhan Buatan & 0,18 & 0,06 & 0,09 & \\
\hline & & Imbuhan Alami & 26,18 & 0,00 & 0,00 & \\
\hline \multirow[t]{4}{*}{2015} & 10,4 & $\begin{array}{l}\text { Pemompaan } \\
\text { Historis }\end{array}$ & 4,85 & 3,16 & 1,94 & 2,95 \\
\hline & & $\begin{array}{l}\text { Pemompaan } \\
\text { Optimal }\end{array}$ & 5,09 & 2,69 & 2,52 & 2,94 \\
\hline & & Imbuhan Buatan & 0,18 & 0,09 & 0,03 & \\
\hline & & Imbuhan Alami & 26,18 & 0,00 & 0,00 & \\
\hline
\end{tabular}




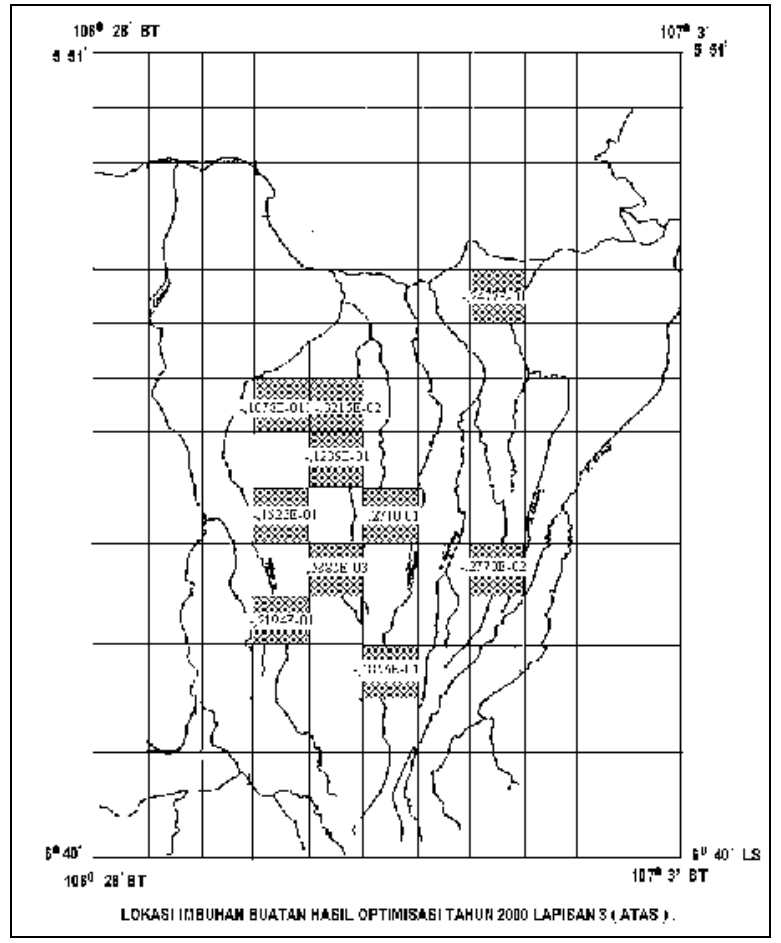

Gambar 5 : Kapasitas imbuhan untuk lapisan air tanah dangkal (m3/dtk)

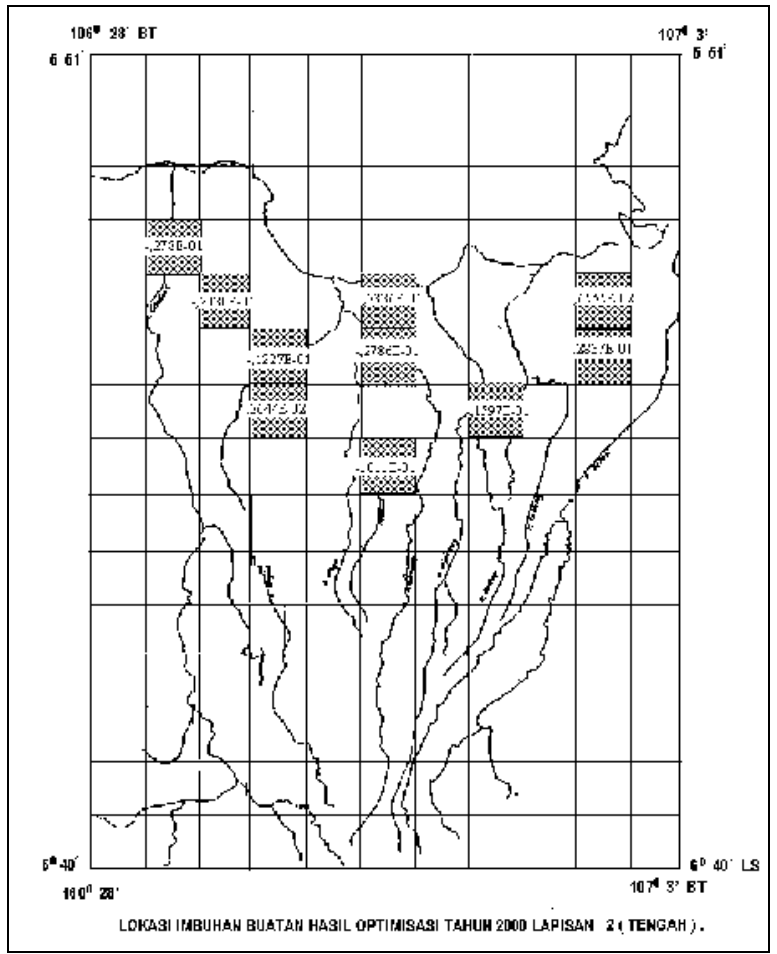

Gambar 6 : Kapasitas imbuhan untuk lapisan air tanah dalam (40 - 140 m, m3/dtk) 


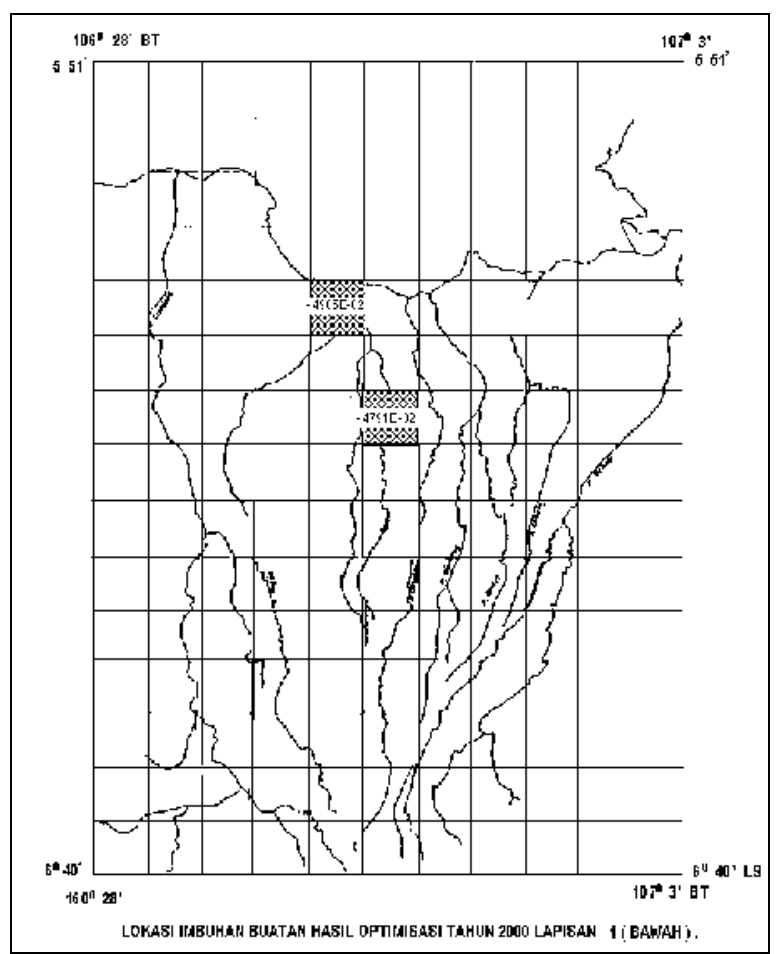

Gambar 7: Kapasitas imbuhan untuk lapisan air tanah dalam (140 - 250 m, m3/dtk) 